This item was submitted to Loughborough's Research Repository by the author.

Items in Figshare are protected by copyright, with all rights reserved, unless otherwise indicated.

\title{
Conversation analysis, language, and sexuality
}

PLEASE CITE THE PUBLISHED VERSION

https://doi.org/10.1093/oxfordhb/9780190212926.013.7

\section{PUBLISHER}

(C) Oxford University Press (OUP)

\section{VERSION}

AM (Accepted Manuscript)

\section{LICENCE}

CC BY-NC-ND 4.0

\section{REPOSITORY RECORD}

Stokoe, Elizabeth, and Susan A. Speer. 2019. "Conversation Analysis, Language, and Sexuality". figshare. https://hdl.handle.net/2134/24790. 


\section{Conversation Analysis, Language, and Sexuality}

Elizabeth Stokoe

Loughborough University

$\&$

Susan A. Speer

University of Manchester

Final version, April 2017

Stokoe, E., \& Speer, S.A. (in press). Conversation analysis, language and sexuality. In K.

Hall \& R Barrett (Eds.), The Oxford handbook of language and sexuality. Oxford: Oxford University Press. 


\title{
CONVERSATION ANALYSIS, LANGUAGE, AND SEXUALITY
}

\author{
ABSTRACT \\ This chapter describes and illustrates a conversation analytic approach to language and \\ sexuality. We start by exploring contrasts between conversation analytic and other \\ approaches to connecting language as a practice and sexuality as an identity topic. We set this \\ discussion in a broader ethnomethodological context, drawing out key themes and debates \\ that have emerged since the inception of ethnomethodological approaches to the study of \\ gender and sexuality in the 1960s, including notions such as 'doing' gender and sexuality and \\ 'passing'. We review briefly the controversial debates about the analytic tractability of \\ identity topics, like sexuality and gender, in the conversation analytic tradition. After \\ summarizing conversation analytic work on sexuality specifically, we illustrate what this \\ approach offers to language and sexuality scholars, showing the methodological steps \\ involved as well as the possibilities for applying findings in the real world beyond scholarly \\ debate.
}

Keywords: language, sexuality, identity, conversation analysis, ethnomethodology, applied research

\section{STUDYING SEXUALITY AND LANGUAGE}

The conversation analytic approach to the study of language and sexuality has been the subject of controversy amongst feminist and other scholars interested in identity. Conversation analysts study identity categories as they are made relevant to unfolding, naturally-occurring, social interaction (Benwell and Stokoe, 2006; 2016). Because of this, 
conversation analysis is antithetical to any approach that starts with a category (e.g., man, woman, gay man, lesbian, bisexual) and proceeds to analyze language on the basis that the category is essentially connected to the language that is produced. So, rather than examine differences in language style, vocabulary, or interaction according to gender (e.g., Lakoff 1973, on women's language) or sexuality (e.g., Leap 1996, on gay men’s English), conversation analysts examine how speakers invoke, draw attention to, ascribe, resist, and so on, the relevance of being an ' $\mathrm{X}$ ', where ' $\mathrm{X}$ ' is any identity category membership (Speer and Stokoe, 2011).

More broadly, within and outside conversation analysis, studies of sexuality, gender, or other identity categories have been challenged by scholars for decades, for treating such categories, often implicitly, as pre-discursive, pre-theorized, natural categories which are biologically determined or socialized from birth and trait-like. This essentialist notion understands human action as varying according to the independent variable of sex/gender/sexual identity (e.g., Uchida 1992). Difference studies are therefore criticized for committing what Deborah Cameron (1997) calls the correlational fallacy, whereby particular linguistic features are attributed unproblematically to one category of person or another. The temptation to 'see' an identity category where it might not be relevant is discussed by Gail Jefferson, one of the founders of conversation analysis:

Working with interactional data, one sometimes observes that a type of behavior seems to be produced a great deal by one category of persons and not all that much by another category. But when put to the test of a straightforward count, the observation does not hold up: Category $\mathrm{X}$ does not after all do this thing significantly more often than Category Y does. It may then be that the apparent skewing of the behavior's distribution across categories is the result of selective observation; noticing with 
greater frequency those cases which conformed to some biased notion held by the observer of how these categories behave. (Jefferson 2004a: 117)

For many feminists and other critically-oriented researchers, 'difference' studies are both theoretically and methodologically circular, and politically unproductive. It is perhaps inevitable that such studies, which prioritize the analyst's taken-for-granted assumptions about difference, will prevent them from seeing gender or sexuality as anything other than a reified, typically dualistic category. Indeed, they start out "'knowing' the identities whose very constitution ought to be precisely the issue under investigation" (Kulick 1999).

Some scholars solve the problem of difference by examining, instead, how identity categories are performed. As Janet Holmes (2007: 52) put it, "the field of language and gender was engulfed in a wave of social constructionism" in the middle 1990s, focusing on the way identity is an "emergent product rather than the pre-existing source of linguistic and other semiotic practices" (Bucholtz and Hall 2005: 588). Much of this work has its 'social constructionist' roots in postmodernism, poststructuralism, and literary theory, drawing heavily on the language of discourse and performativity in, for example, Foucault (1972), Butler (1990), and Bauman (2004).

The constructionist turn is also somewhat rooted in ethnomethodology, in Harold Garfinkel's (1967) ground-breaking work on the social production of gender (although see Speer 2005 and Stokoe 2008, on the similarities and differences between ethnomethodology and constructionism). Through a case study of Agnes, a 19-year-old male-to-female transsexual, Garfinkel analyzed the practices involved in 'passing' and the "managed achievement of sex status" (1967: 116). Thus Garfinkel's task was to "understand how membership in a sex category is sustained across a variety of practical circumstances and contingencies, at the same time preserving the sense that such membership is a natural, 
normal moral fact of life" (Zimmerman 1992: 195). These ideas were developed by Suzanne Kessler and Wendy McKenna (1978) and Candace West and Don Zimmerman (1987), who coined the phrase "doing gender" to refer to the idea that gender is a social accomplishment (see Jurik and Siemsen, 2009; West and Zimmerman 2009). From this perspective, sex, like gender, is not a biological or socialized essence or trait that exists prior to and outside of discourse. The male-female dualism is not 'natural'. Instead, both sex and gender are things that one does rather than things that one has; they are activities rather than attributes, socially constructed belief systems rather than natural, inevitable, and timeless facts (for an analysis of passing 'practices' using CA see Speer 2011, and Speer and Green 2007).

Despite the radical potential of constructionist approaches, however, they suffer a number of problems in their empirical translation (Speer 2005; Stokoe 2008). Studies about the 'construction of identity' often end up making essentialist-sounding claims, particularly those that collect the talk of, say, heterosexual women, in interviews or natural settings, and then look at how the participants perform heterosexual femininity / femininities. There is rarely a notion in such work of people not performing identity. If the data do not 'look like' recognizable hetero-femininity, the 'finding' is that identity is not what we thought it was, or that it is variable, inconsistent, multiple, or fragmentary (Edwards and Stokoe, 2004). Thus the performance of identity is explained or accounted for in a somewhat circular fashion, leaving what Irving Velody and Robin Williams (1998) call a "realist residue." This type of 'constructionist' research, therefore, buys back into the difference framework that it was originally designed to replace, and inadvertently re-introduces essentialism and determinist understandings of gender identity construction 'by the back door' (see Speer 2005, Stokoe 2005, 2008). As Jack Sidnell notes: 
There is an underlying tension here in so far as many researchers advance antiessentialist, theoretical conceptions of gender (suggesting that gender emerges through the practices of talk) but at the same time employ the very same categories in their analysis. The theoretical notion of 'performativity' offered as an anti-essentialist antidote, is problematic in so far as it presupposes some 'real' set of actors who inhabit the roles of the dramatis personae. (Sidnell 2003: 347)

For us, a more radical solution to the problem of identity essentialism is conversation analysis (Speer and Stokoe 2011). We turn now to explain what conversation analysis is, and the affordances of such an approach for studying sexuality.

\section{CONVERSATION ANALYSIS AND TOPICS OF IDENTITY}

Conversation analysis (CA) has its roots in ethnomethodology, a sociological discipline that was developed by Harold Garfinkel (1967). It originates in the work of the American sociologist, Harvey Sacks, and his colleagues Emanuel Schegloff and Gail Jefferson. Sacks's aim was to develop an alternative to mainstream sociology: an observational science of society and social action that could be grounded in the "details of actual events" (Sacks 1984: 26). CA involves the study of transcripts of recorded everyday and institutional talk, focusing on the turn-by-turn organization of interaction. For Schegloff (1996: 4), a key figure in the subsequent development of CA, talk-in-interaction is "the primordial scene of social life ... through which the work of the constitutive institutions of societies gets done. It is through talking that we live our lives, build and maintain relationships, and establish who we are to one another" (Drew 2005: 74, emphasis added).

CA involves the study of transcripts of recordings of ordinary and institutional talk of various kinds, focusing on the turn-by-turn organization of talk and embodied conduct in 
interaction. CA is primarily concerned to describe the methods and procedures speakers use to coordinate their talk to produce orderly and meaningful conversational actions. These procedures are not idiosyncratic, but display relatively stable patterns and organized regularities that are oriented to by participants. Examples of patterns and topics studied include how people take turns in conversation, what it means to overlap with another speaker or produce a delayed response, how conversations are opened and closed, how people make reference to themselves and each other, how actions (e.g., complaining, questioning, assessing, inviting, etc.) are accomplished, how turns at talk are designed and formulated, how people solve problems in hearing, speaking, and understanding, and a range of other conversational phenomena (Sacks 1992; Schegloff 2007; for an introduction see Sidnell 2010). The goal of CA is to establish the structural frameworks that underpin and organize such regularities in interaction: "the structures of social action" (Atkinson and Heritage 1984).

With regards to sexuality, gender, or any identity category, conversation analysts ground analysis in what participants do and say, rather than in what analysts take to be relevant as a function of their hypotheses, research questions, politics, or theory. From this perspective, then, in order to warrant an analytic claim that a particular category is relevant to any stretch of interaction, the analyst must be able to demonstrate that such identities are linked to specific actions. There are two key issues here for conversation analysts. The first is the problem of relevance: Given the indefinitely extendable number of ways any person may be categorized, how should we decide which category from a range of potential identities is relevant? The answer is to go by what is demonstrably relevant to participants "at the moment that whatever we are trying to produce an account for occurs" (Schegloff 1991: 50). The second issue is that of procedural consequentiality: If we can establish that a particular identity category is relevant, can we see that it is consequential for participants, in terms of its 
trajectory, content, character, or organizational procedures? Does it have "determinate consequences for the talk?" (Heritage 2005: 111).

Thus, to the extent that identity is relevant to the analysis of the extract at all, it is in terms of the participants' "activity-relevant identities" (Schegloff 1997: 180). In Schegloff's data, it is activity, rather than power or identity, which accounts for what the participants are doing. Within Schegloff's framework, there must be explicit grounds for characterizing the parties as, say, 'a man', 'lesbian', and so on. Without this linkage, claims about the relationship between identity category and linguistic feature (e.g., interruption) are, for Schegloff, "profoundly equivocal” (2001: 309, see also Kitzinger 2008) and a matter of “theoretical imperialism" (1997: 167). This is because speakers are not just 'men' and 'women' but are members of an indefinitely extendible number of categories. So, in order to claim a link there needs to be some "analytic criteria on the basis of which a speaker can legitimately be heard to be speaking as a member of one category rather than another" (Land and Kitzinger 2011).

Schegloff’s (1997) paper generated enormous interest amongst feminists and other critically oriented researchers, who began to work through the implications of Schegloff's arguments for their own research and analytic practices. It has generated considerable (and heated!) debate in the field in recent years. Some argued that although Schegloff's 'exclusive' focus on participants' orientations may be "extremely revealing" such an approach is restrictive and impractical (Wetherell 1998: 404, Wetherell 2007), and cannot account for the invisible workings of power, the unsaid or what is not oriented to (Frith 1998), the pervasive, 'omnirelevance' of gender (Weatherall 2000), or the fact that very few feature of (English) language explicitly index gender (Ochs 1992). Indeed, some feminists suggest that Schegloff's approach "limits admissible context so severely that only the most blatant aspects of gendered discursive practice, such as the overt topicalizing of gender in conversation, are 
likely candidates for Schegloffian analysis" (Bucholtz 2003: 52; see also Enfield [2007] on going beyond the "Members-Only Filter"). Many language, sexuality, and gender researchers reject $\mathrm{CA}$ on this basis, preferring to recruit 'wider' contexts, politics, and ideology to make claims about what is happening in a piece of data. However, there is a seam of work in conversation analysis that illustrates the payoffs for adopting this robust and disciplining approach to make claims about the relevance of sexuality to interaction and, more broadly, social life (see Speer and Stokoe 2011). We review some of these studies in the next section.

\section{Conversation analytic studies of sexuality}

Within conversation analysis as a field, a relatively small percentage of publications focus on gender, and many of those incorporate Sacks's work on membership categorization alongside a sequential analysis (see Stokoe 2012). Most CA studies pay attention to the systematic, patterned unfolding of interaction, turn-by-turn, in domestic and institutional settings of all kinds, without referring to or focusing on the relevance of identity concerns. Within the work that does focus on gender (for examples and reviews, see McIlvenny 2002; Speer 2005;

Stokoe and Weatherall 2002; Speer and Stokoe 2011), even less focuses on sexuality as its primary analytic target, despite their mutual co-implicativeness.

Within the literature that has grown during the past decade or more, there are three related thematic threads. The first thread attends to the way sexuality is made relevant by speakers in the course of social interaction (see Wilkinson 2015). The second focuses on the explicit and implicit construction of heteronormativity (e.g., Kitzinger 2005; Murphy 2014; Riggs 2013) and sexist, heterosexist/homophobic talk (see Speer 2002; Speer and Potter 2000, 2002; Weatherall 2015). A third attends to how talk about sex is occasioned and managed (Speer 2013) and to other sex-related topics, such as issues of consent and sexual violence (e.g., Ehrlich 2002; Kitzinger and Frith 1999). Some strands have an emancipatory agenda, as 
Sue Wilkinson and Celia Kitzinger (2007: 230) write: “we focus on mundane, routine, everyday forms of oppression: the 'micro-inequalities' of social life ... We are committed to understanding how sexist and heterosexist presumptions are threaded through the ordinary practices of talk and interaction that, cumulatively, constitute an oppressive social order. Conversation analysis offers a powerful and rigorous method for exposing the mundane oppressions of everyday life." In the conversation analytic tradition, then, the focus is on how "sexuality is constructed in and through talk-in-interaction ... [and] when (and how) sexuality is relevant in talk" (Wilkinson 2015: 1115).

It is clear that the use of CA for the study of sexuality, gender, and language is controversial. However, we want to show in the next section how powerful an analysis can be when claims about the relevance of sexuality can be evidenced from the participants themselves. We show how conversation analysis proceeds, from a dataset of recorded and transcribed interactional encounters. We will show how gender and sexuality are made relevant in such encounters and thus illustrate the distinctive approach of CA to the study of these fundamental categories of social life.

\section{STUDYING SEXUALITY USING CONVERSATION ANALYSIS}

To showcase conversation analysis as a methodology, and particularly how it may be applied to an analysis of sexuality and gender, we draw on a collection of over 250 telephone calls between potential customers of a window and conservatory sales company service and the salespeople who answered the phone, collected by the first author. Callers consent to have their calls recorded for quality and training purposes. The recorded data were anonymized digitally (to remove / transform names and other identifying features, and to change the pitch of voices) and transcribed using Gail Jefferson's (2004b) system for conversation analysis (see Appendix). The system does not just attend to what is said, but how it is said. It encodes 
detailed information to capture, forensically, the way talk is delivered, such as its pacing and timing, the start and end of overlapping talk, and other interactional features. As we will show, such features are consequential for understanding the fine-grained/subtle and nuanced ways in which sexuality is made relevant to the ordinary conduct of social life.

A first step in conducting CA is to ascertain the key projects or activities that comprise the complete encounter, from opening the call to closing it. Actions like requesting, offering, describing, questioning, and so on, are common in institutional encounters of all kinds. Once these activities have been identified, analysts collect together all instances of, say, how a request for service is done. By collecting multiple instances of the same basic activity, CA proceeds by examining how that activity is designed and how different designs may lead to different conversational outcomes - from the next turn to the next sequence.

In the windows and double-glazing sales calls, the salesperson has to get the customer's name, once it is ascertained that the caller wants to proceed with whatever service they have requested and been offered (see Benwell and Stokoe 2016; Stokoe and Sikveland 2015). Our interest in these calls is how asking about names both implicitly and, sometimes, explicitly, indexes the sexuality of the caller (see Stokoe, Sikveland and Huma, in press). We will see that the questions presume a default heterosexual identity. Consider Extract 1, in which the windows salesperson (W) asks the caller (C) for his surname.

\section{Example 1: WC-43}

$1 \quad$ W: And u::m: can I take y’surname please $\uparrow$ si:r.

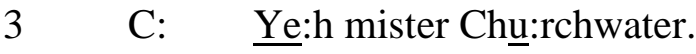

$5 \quad$ W: $\quad$.hh that's $(0.2)$ cee aitch you are $<$ cee $:>$ double you ay tee ee $\downarrow$ are. 
$7 \quad$ C: $\quad$ That's it love, $=$

$8 \mathrm{~W}: \quad=\#$ Lovely.\# (0.2) Oka:y,=is- is it just your $\uparrow$ se:lf? or is it mister'n $\uparrow$ missu:s?

$9 \quad \downarrow$ or. .hh

10 C: Mister an' missus yeh.

11 W: \#Lovely.\#

Within a series of questions about who the caller is, their address, and so on, W first establishes C's surname. W solicits (line 1) then confirms the spelling (line 5) of the caller's name. At line $8, \mathrm{~W}$ then proceeds to ask a more complex question about C's marital status. W first asks if it is "just your个se:lf?", in a yes-no interrogative formatted question. Note the difference between W's first question, which seeks information (W cannot guess at C's name!) and the second substantive question “is it just your个se:lf?”. The second question contains a candidate answer; she does not ask “can I take your marital status?".

Before $\mathrm{C}$ responds to the second question, $\mathrm{W}$ reformulates the question as an alternate interrogative with options (“or is it mister’n $\uparrow$ missu:s?”), and a further trail-off “ $\downarrow$ or." that C could complete if neither possibility has yet been named by W. W therefore offers, in pursuit of C's 'marital status' category membership, different possibilities for him to select, confirm or reject. These redesigned questions handle the epistemic asymmetry between $\mathrm{C}$ and $\mathrm{W}$; that is, while $\mathrm{W}$ displays her normative knowledge about how the world is organized in terms of heterosexual couples living together and buying windows, only $\mathrm{C}$ knows about his actual living arrangements and, furthermore, is entitled to do so; $\mathrm{W}$ is not entitled to make a 'best guess'. W's subsequent questions both prefer a 'yes' confirmation, but the 'or' handles the possibility that $\mathrm{C}$ occupies an alternative category. But the questions, and their order of 
presentation, reveal what $\mathrm{W}$ takes to be the most likely category that $\mathrm{C}$ is a member of single or heterosexually married. In 10, C confirms that he is "Mister an' missus yeh.".

In Example 2, a similar series of questions produces a different response from another male caller.

\section{Example 2}

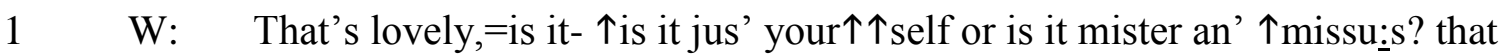
we're $\uparrow$ see[ing or. ]

$3 \quad \mathrm{C}: \quad$ [It's mister] (it's/just) misterh

$4 \quad$ W: Just mister Higgins, $=[$ that's great stuff $\mathrm{u}: \mathrm{m}, \mathrm{hh}$

5 C: $\quad$ YYep.

At line 3, in overlap, C's response addresses the yes-no interrogative question in the first part of W's question, which contains several options of marital status category within it. After other options are listed, C provides a response to the interrogative, confirming that "It's mister". As in many cases of overlapping talk, C then redoes his answer 'in the clear', outside of the overlap. Here, he repairs his response by inserting the word 'just'. W's intonation in

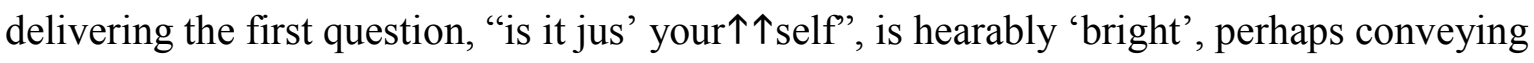
that being 'just yourself' is 'no problem' and not a marked category, or something that may require sympathy. This analysis is supported by W's confirmation of C's answer at line 4: "Just mister Higgins," which is swiftly followed by an assessment "=that's great stuff". So the fact that $\mathrm{C}$ is 'single' (or widowed, or divorced) is not a problem for W; W has no stake in his answer. Such questions, particularly with the trail-off 'or', are similar to those found in speed-dates in which one dater may ask another, "have you been married, or..." (Stokoe 2010). In this context, it becomes clear that the preferred response (structurally) is 'yes (I 
have been married)', but the trail-off mitigates the initial the push for a 'yes' response (with the initial yes-no part of the question design) and positions the questioner as 'happy with either response'.

In Example 3, the issue of whether or not callers are 'single', ('heterosexually) 'married', or something else arises as W makes arrangements to visit the caller.

\section{Example 3: WC-33}

$1 \quad \mathrm{~W}: \quad \underline{\mathrm{U}}: \mathrm{m}$ : so I just need t'have a look on the diary now an' see when I can: arrange for: somebody t- to pop an' see y'both.=obviously measure up an' .hh an' get

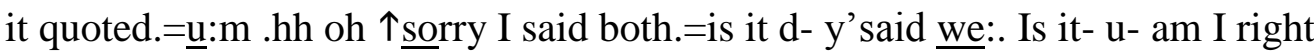
in assuming it's £mister an' missus,£

$6 \quad$ C: $\quad$ Yes.

$7 \quad$ W: $\quad \underline{\text { O:: }}$ h right. $=$ okay.

8

$9 \quad$ W: $\quad{ }^{\circ}$ \#ister an’ missus. ${ }^{\circ}$

Here, $\mathrm{W}$ formulates her presupposition that the caller is (heterosexually) married, by proposing to see them 'both' (line 2), and then in her subsequent question to W ("Is it- u- am I right in assuming it's £mister an' missus, £”). Note the detail in her question, which is prefaced with an apology for making an assumption, and then starting to ask "is it", which presumably is headed towards the question "is it mister and missus". However, she repairs this to ask whether or not her assumption is correct. Here is one crux of the matter. Titles mister and missus - carry with them particular sorts of information in English. More specifically, the title 'missus' specifies a woman's heterosexual and marital status in a way 
that 'mister' does not, making such terms highly gendered and the subject of much attention in feminist linguistics over the decades. Additionally, it is also a heterosexist assumption, which positions a woman as 'belonging to' a man. But C is more entitled to know about his marital status than W, and so her presupposition that the company will visit 'both' is problematic. Her subsequent repairs reveal that and how "speakers are exquisitely sensitive to their epistemic positions relative to addressees, as a condition of developing a turn at talk" (Heritage, 2012: 31). The turbulence created by making, then correcting, presuppositions, is revealed in the gap that develops at line 5 , before $\mathrm{C}$ confirms that it is indeed 'mister and missus' at line 6, with a minimal 'yes' response (cf. Examples 1 and 2).

In Examples 1-3, W has addressed these questions to male callers. In Example 4, W asks a female caller a similar series of questions. Our interest here is that, rather than 'miss' being the first option, W's question presupposes that the caller is a 'missus' and/or a wife even if she lives alone. 'Missus' more directly implies that the caller has a spouse in a way that 'mister' does not.

\section{Example 4: WC-23}

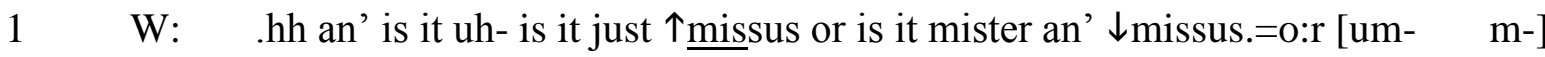

$2 \mathrm{C}$ :

[(Only me.)]

3

$4 \quad$ W: \#U-\# ok- $\uparrow \underline{s}$ o y- is it- i- it's just yourself is it.=[\#sorry.\#]

5

C:

[ (Yeh-) ] I live with my mum.

$7 \quad \mathrm{~W}: \quad \uparrow \uparrow \underline{\mathrm{Oh}} \uparrow$ right okay,.hh 
W's questions, again built from an assumption about the most likely domestic arrangements of the caller, generates the response "Only me." from C. Like Examples 1 and 2, W starts with the 'single' category, producing a version of "is it just yourself". Her choice of language is particularly interesting given that $\mathrm{C}$ is asked if it is "just missus", as if 'missus' is a title appropriate for a single woman. $\mathrm{W}$ then goes on to propose that it might be 'mister and missus'. Only then does the caller begin to answer. Unlike Example 2, however, in which W repeats 'Just mister' without a glitch, her response to $\mathrm{C}$ is delayed (line 3), full of perturbation (hesitations and cut-off sounds), and a formulation of what she takes to be the upshot of C's response “ $\uparrow \underline{s}$ o y- is it- i- it’s just yourself is it.". Here, then, W struggles with a 'single’ response to a 'missus' caller, which results in C providing an account for her situation "YehI live with my mum." (line 5) (although it does not explain why C refers to herself as 'missus'). After another delay, W’s response displays a 'change of state' (Heritage, 1984),

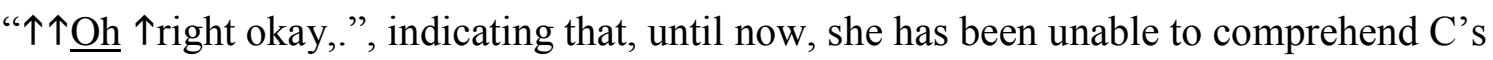
domestic situation as a 'missus' who is 'just herself' - despite actually living with her mother. In Example 5, W produces a third option for $\mathrm{C}$ to respond to.

\section{Example 5: WC-2}

$1 \quad \mathrm{~W}: \quad \uparrow$ Is it- is jus' $\uparrow$ mi:ster? or is it mister an' mis $\uparrow$ sus? $\uparrow$ or mister an’ a £partner£ [that (we're/we'll) see-]

3 C: $\quad[$ No i- ju- $]$ no it's just mister. $=$

$4 \quad \mathrm{~W}: \quad=$ Oh it's just- yeah.

Note that W is hearably smiling as she “produces the word “£partner£”. Although 'partner' could refer to a man living with a woman in an unmarried situation, the intonation is marked. It is inaccessible from the data whether or not $\mathrm{W}$ is offering $\mathrm{C}$ the possibility that he is gay 
and living with a man, or whether she treats this option as humorous because it is in some way 'politically correct'. Either way, W produces the 'mister and a partner' option in a different way to 'just mister' and 'mister and missus'.

The final example, to another female caller, shows the same problem with the use of 'both' as we saw in Example 3, and similar turbulence in the subsequent trajectory of the call as $\mathrm{C}$ reveals her single status.

\section{Example 6: WC-50}

1 W: .hh awri.ght? so that's my little checklist done.=So [.hh $\uparrow \uparrow \underline{w h e n ' s] ~ a ~} \uparrow$ good=

$2 \mathrm{C}$

[ Okay then, ]

3 W? $=\uparrow$ time f'us t'pop along an' see y'then or sort'f see you both $\downarrow_{\text {sorry. }}=$ if it's

4 mister an' \#missus,\#

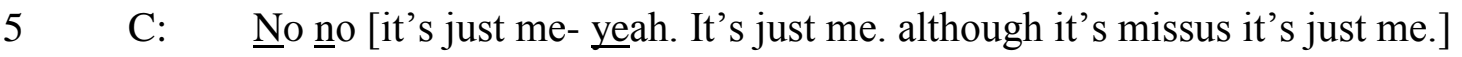

Immediately preceding the call, $\mathrm{C}$ has given her name as 'Mrs Bedford'. It is on this basis, then, that W proposes that the firm will see them 'both'. Note the position of 'both' in line 3; it is in a repair of W's initial proposal that the firm will see just C. W then corrects herself, on the basis that it's "mister an' \#missus,\#”, leaving both options open. C then both confirms that it is 'just me' as well as correcting W that "although it's missus it's just me" (line 5). Here, then, $\mathrm{W}$ and $\mathrm{C}$ jointly orient to the cultural assumption that a member of the category 'missus' is heterosexually married with a relevant 'mister'.

Overall, then, we have seen, much like Kitzinger's (2005) analysis of out-of-hours calls to doctors' surgeries, how matters of identity, in terms of normative assumptions about people's category memberships, may produce turbulence in what are quite banal interactional episodes. This turbulence is similar to Kitzinger's, who focused on caller's responses to 
questions that also presuppose a heterosexual relationship. In her data, callers are put in the position of having to 'come out' as a lesbian or gay couple and household. In our calls, callers frequently have to reveal /account for their (non-normative - according to the company's discursive practices) domestic arrangements and relationship statuses to satisfy the organization's heteronormative 'script' of questions for information-gathering.

Having provided a brief empirical example of how sexuality can be made to matter in the course of social interaction, and in getting things done, we show how this sort of analysis can have a practical outcome.

\section{APPLYING CONVERSATION ANALYTIC WORK ON SEXUALITY}

In the final section, we show how a conversation analytic study of identity topics, including sexuality and gender, can have impacts outside scholarly debate and analysis. To do this, we draw on a further dataset collected and analysed by the first author: a collection of telephone calls into community mediation services. These services handle disputes between neighbors, either at the request of one or both parties or at the instigation of organizations themselves. For example, in the UK, police become involved if disputants engage in criminal activities (e.g., assault, criminal damage, public order offences). Alternately, a neighbor may call community mediation services who will then contact the other neighbor.

In some mediation service encounters, clients may say something potentially prejudiced about the neighbour they are complaining about. That is, clients make identity matters (both their own, as the kind of person who might make sexist or homophobic remarks, and the identity of the person being described) relevant to their complaint, leaving mediators in the position of having to respond. Elsewhere, we have shown that mediators respond to what we have referred to as '-isms' (such as racism, sexism, heterosexism) in particular, 
patterned ways (see Stokoe 2015). Because mediators are guided by the principle of impartiality, responding to clients' potentially prejudiced comments is a particular challenge.

Such analytic observations may be turned into practical outcomes for service providers; that is, the mediators whose institutional practices are under analytic scrutiny. Over the past two years, one of us (Stokoe) has developed a method called the 'Conversation Analytic Role-play Method' (CARM, Stokoe 2011, 2014), within a broader range of conversation analytic interventions in the communication practices of professionals of all kinds. CARM takes findings from conversation analytic research as the basis for communication training. To date, CARM has been used to train professionals from mediators to police officers, and salespeople to doctors. Conversation analysts already have a strong track record in delivering practical and policy intervention in institutional settings ranging from education and medical communication, to therapy and helpline interaction (see chapters in Antaki 2011). In contrast to traditional methods for training 'communication skills', which are often based on simulated interaction and role-play, , CARM uses research about actual interaction, and the identification of practices that comprise the setting under investigation, as a basis for training. In the context of applied CA, CARM has been described as "the most significant ... development" (Emmison 2013), and it demonstrates how designedly largescale qualitative work can generate impact beyond the academy.

To turn our research on 'isms' into a CARM workshop, the first step was to identify examples of clients' talk in which they made a potentially sexist, racist or homophobic comment. Mediators' responses fell into one of two broad categories, either deleting (e.g., through reformulating the issue; a kind of embedded correction: cf. Jefferson 1987) or challenging the '-ism' (e.g., by admonishing the client). Both sorts of responses involve disaligning or disaffiliating with the caller or client rather than adopting the mediationmandated impartial stance (see Stivers 2008). Like Whitehead (2015) observed in radio call-in 
hosts' responses to possibly racist callers, mediators' responses are dispreferred; some contain the classic markers of such turns, including delay or silence.

In Example 6 below, the caller's neighbor has accused her of making noise and also being racially abusive. Here, the caller is defending herself to the mediator against this 'false allegation'.

\section{Example 6: EC-21}

$1 \quad$ C: $\quad(\ldots)$ she's already been down to the council $>$ offices $<$.hh made

2 false allegations about- sayin' I've- (0.3) give her a lot of

3 raci:sm, (0.6) [an' I have ne:ver call- I did admit t- $\underline{\text { months }}=$

$4 \quad \mathrm{M}: \quad\left[{ }^{\circ} \mathrm{Mm}: \mathrm{m} .^{\circ}\right.$

$5 \quad$ =and months ago I had a big barney with her an' I did call 'er a

$6 \quad$ loud- mouthed fuckin'*le(h)s:bian.

In this call, C's denial of racial abuse is shored up by her admission of another -ism: calling her neighbour "a loud- mouthed fuckin" *le(h)s:bian." (lines 1-6). The logic of this admission is that, if $\mathrm{C}$ is the kind of person to admit when she makes prejudiced comments, then she would also admit the racism (Edwards, 2006; Stokoe, 2009). This also establishes the neighbour as one who makes false accusations; that she could have (truthfully) accused C of calling her "a loud- mouthed fuckin" *le(h)s:bian", and C would have admitted to having done so, but instead she has (falsely) accused her of racial abuse.

In CARM workshops, the participants see and hear the first six lines, and then the transcript and the sound stop. This way, they live through the interaction in real time, enabling them to consider what they might do in a real, rather than hypothetical, situation. Participants are asked to discuss a series of questions: Is there a possible -ism in the data? Is the caller 
homophobic? If yes, why? If no, why not? And, finally, what will your response be, as a mediator, in the next turn? This generates discussion about the nature of prejudice, as well as the nature of mediation itself (a practice which prizes impartiality, which is most sorely tested in cases such as these; see Stokoe and Edwards 2007).

Then the next turn is played, and the extract unfolds slowly, turn by turn, each time stopping for participants to discuss the mediator's reaction and their own stance towards the caller.

\section{Example 7: EC-21 (contd.)}

7

$8 \quad$ C: $\quad$.hhh but that is all I have ever called 'er.

As we can see, $\mathrm{M}$ does not respond to C's turn and $\mathrm{C}$ begins to minimize her claim. Stokoe (2015) showed that, in the light of no affiliation or alignment from mediators, callers typically withdraw from their first turn, by adopting an ironic/humorous stance, or by (re)formulating the -ism as based in empirical fact rather than in their prejudiced disposition. A clear route out of these sequences is to return to procedural matters, with both clients and mediators using this practice. We can see this pattern in the remainder of the extract.

\section{Example 7: EC-21 (contd.)}

9

$10 \quad \mathrm{C}: \quad$ Once.

12 C: Out of temper. 
14 C: But she's been down there: (0.2) an' said I've called 'er this

15 that an' the other I don't know what she's said,

$16 \quad(0.5)$

17 C: But I know she's been down there: an' made (.) race allegations

18 against me,

$19 \quad(0.7)$

20 C: Right- because I: went down'ere the next day an' I've done

21 exactly the same.=because she ha:s made racial abuse to me. she's

22 called me a wh:ite this a whi:te that, .hhhh

$23 \quad(0.2)$

24 C: An' stuff:.

$25 \quad($.

26 C: $\quad$ Right.=an' no: w I think it's gone too fa:r.

$27 \quad($.

28 C: Because they said about the mediation an' that a- an' I'm

29 [not int]erested no more.

$26 \mathrm{M}: \quad[\mathrm{Mmm}]$

$\mathrm{M}$ remains silent and does not align with the caller at all. $\mathrm{C}$ withdraws across subsequent turns (lines 8-12), minimizing and delimiting her prejudiced action as one-off and done in temper, rather than as systematic and done to reveal a dispositional bias against lesbian women. The extract is striking in the lack of any spoken turns from M, who produces no continuers or anything else in numerous gaps. C makes counter allegations of racial abuse (lines 14-24), but $\mathrm{M}$ does not align with $\mathrm{C}$ in response. Indeed, $\mathrm{M}$ hearably aligns again only after $\mathrm{C}$ starts to talk about the mediation process (and refuses to mediate). In this excerpt, 
then, $\mathrm{C}$ talks herself out of mediation, possibly because she treats M's silence as partial; as explicit misalignment. This is interesting because the goal, for mediators, of initial calls is to convert callers to the service into clients; without clients, community mediation services are unsustainable. It is also interesting because, rather than remain impartial, M 'takes sides' against the caller.

Consider a second example. Example 8 comes from another inquiry call between a mediator and potential client. It is in such calls that problems are first formulated and offers of or requests for mediation are made. The mediator's job is to elicit a summary of the problem from the potential client; explain what mediation is, and offer it to them. C's problem has to do with his female neighbor's noise, and he has claimed that the problem is exacerbated by her visiting boyfriend. We join the call as it comes towards its closing. $\mathrm{C}$ has agreed to mediate.

\section{Example 8: EC-13}

$1 \quad \mathrm{M}: \quad\left[{ }^{\circ} \mathrm{Yeh}^{\circ}\right.$

2 C: [.hhh I wouldn't mi:nd the bloke's most probably got a

3 family of his own somewhere else. .hhh

4

$5 \quad \mathrm{C}: \quad$ You kno:w?

$6 \quad \mathrm{M}: \mathrm{Mm}$

8 C: An' 'e's comin' down 'ere for a little bit of fá:ncy bit.

10 C: Heh heh .hhh d'you know what I me:an. 
C suggests that his neighbor's "bloke" is already married, thereby implying that she is his 'mistress', or "fa:ncy bit" (line 8), making her sexuality relevant to the ongoing project of complaining about her (see Stokoe 2013). After a gap develops in which M says nothing (line 4), C pursues an affiliative, 'co-member' response from M, as if they are 'friends' talking, or as two 'heterosexual men', perhaps, rather than as 'mediator-client' (line 5). M responds with a continuer (“mm”), which aligns minimally with C's general project of characterizing his neighbor but does not affiliate or take a stance on it (for example, “oh yes, I know!”; see Stivers 2008). At line 10, however, C pursues M's affiliation once more, asking him to display shared knowledge of, and a shared stance towards, what 'adulterous' people are like. Again, in the CARM workshop, participants formulate, discuss, and evaluate possible responses. Here is what $\mathrm{M}$ actually said in response.

\section{Example 8 (contd.)}

12 M: Ye:s I [understand] what you're saying yeah:

13 C: $\quad\left[Y^{\prime}\right.$ know? ]

$15 \quad \mathrm{M}: \quad{ }^{\circ} \mathrm{Yeh}^{\circ}$

17 C: $\quad$ Because [that's what she's lị:ke.

$18 \quad$ M: $\quad[($ Is it cos-)

20 M: Ye:::ah. hh okay.=so $\cdot$ hh w'll- $\mathrm{w}-[$ I'm going to contact $]=$

$21 \mathrm{C}$

[ ( coughs $)) \quad]$ 
Like the mediator in Example 7, M does not display affiliation with $\mathrm{C}$. At line 12, he states that he understands what $\mathrm{C}$ is "saying", but not that he agrees with what $\mathrm{C}$ 'means'. Neither does he reciprocate C's laughter. And, following further pursuit from C (line 17), M returns to procedural issues.

Because mediators are expected to display themselves as impartial, they avoid displaying a stance towards the problems described by clients. One issue that arises, as we see particularly in Example 7, is that clients will often pursue affiliation, or displays of stance, and often resist offers of mediation when such affiliation is not forthcoming. In CARM workshops about '-isms', participants see mediators doing one of three things in response: (1) reformulating problems by deleting the prejudicial element, (2) moving the discussion towards mediation or procedural issues, and, occasionally, (3) confronting clients about their prejudice (see Stokoe, 2015, for an example of this and other further instances). They therefore get to see actual mediators dealing with actual interactional problems, as well as potential solutions to the conundrum of avoiding affiliation with problematic stances while keeping the client in mediation.

CARM provides participants with a unique opportunity to scrutinize real recordings of mediation, rather than train only with role-play, and discuss (and argue about) best practice. The implications of CARM for other workplaces might include recording day-to-day activities, such as meetings. Staff could then identify, and scrutinize, practices that may be problematically gendered or heterosexist, or problematic in some other way, as a basis for discussion and as a source of training materials. Crucially, we can see how participants and professionals understand and handle issues of identity in real-life settings that matter. Unlike many traditional approaches to communication skills training, which often begin and end with presumptions about problematic categories, or use hypothetical cases and simulated 
interaction, conversation analytic research on language and sexuality has a particular integrity in both its research findings and the application thereof. Because conversation analysts aim to reveal the categories that matter to participants, which may or may not be the ones that matter to academics (in the first instance), observations about the relevance and salience of sexuality and gender are hard to challenge. Furthermore, the way people talk about sexuality in real encounters, and use gender and sexuality categories encounters that matter to them (e.g., callers to mediation want mediators to treat them as the reasonable party and their neighbor as the problem), means that professionals learn directly the outcome of different ways to respond. They also think about 'what counts' as a reference to gender and sexuality or an ism - grappling with much the same issue as scholars of these identity categories.

\section{CONCLUDING REMARKS}

In this chapter, we have described and illustrated a conversation analytic approach to language and sexuality. We identified the crucial and distinguishing analytic move made by conversation analysts, which is to ground any analysis of sexuality, gender, or other identity categories in the visible orientations of speakers themselves, endogenous to the interaction. We have illustrated the method using transcribed recordings of people engaged in a mundane activity; that of buying windows. But we showed how, systematically across this dataset, potential buyers of windows had their sexual identity made relevant to ongoing business simply through the heteronormative practices of eliciting their title and name by salespeople. We then showed how analysis of speakers making sexuality and related identity matters relevant in other types of encounters can be used by practitioners to reflect on cases of potential homophobia or sexism, and take empirical findings about how to respond into their communicative practice. 
The debate about whether or not conversation analysis is or can be feminist, emancipatory, political, and theoretical, is unlikely to be halted by the work we have presented and overviewed in this chapter. But we hope that the real-world affordances of conversation analytic research excite readers and show how the gap between studying real life as it happens, and applying it to real life, showcases new territory for language and identity scholars.

\section{APPENDIX to Jefferson (2004)}

\section{REFERENCES}

Antaki, Charles ed. 2011. Applied conversation analysis: intervention and change in institutional talk. Basingstoke: Palgrave Macmillan.

Atkinson, J. Maxwell and Heritage, John eds. 1984. Structures of social action: Studies in conversation analysis. Cambridge: Cambridge University Press.

Bauman, Zygmunt 2004. Identity. Cambridge: Polity Press.

Benwell, Bethan and Stokoe, Elizabeth. 2016. Ethnomethodological and conversation analytic approaches to identity. In The Routledge handbook of language and identity, ed. Sian Preece, 66-82. London: Routledge

----. 2006. Discourse and identity. Edinburgh: Edinburgh University Press.

Bucholtz, Mary. 2003. Theories of discourse as theories of gender: Discourse analysis in language and gender studies. In The handbook of language and gender, ed. Janet Holmes and Miriam Meyerhoff, 43-68. Oxford: Blackwell.

Bucholtz, Mary and Hall, Kira. 2005. Identity and interaction: A sociolinguistic cultural approach. Discourse Studies, 7:4-5, 585-614. 
Butler, Judith. 1990. Gender trouble: Feminism and the subversion of identity. New York Routledge.

Cameron, Deborah. 1997. Demythologizing sociolinguistics. In Sociolinguistics: A coursebook and reader, ed. Nicholas Coupland and Adam Jaworski, 55-67. Basingstoke: Macmillan.

Drew, Paul. 2005. Conversation analysis. In Handbook of Language and Social Interaction, ed. Kristine L. Fitch and Robert E. Sanders, 71-102. Mahwah, NJ: Lawrence Erlbaum. Edwards, Derek. 2006. Facts, norms and dispositions: Practical uses of the modal would in police interrogations. Discourse Studies, 8:4, 475-501.

Edwards, Derek and Stokoe, Elizabeth H. 2004. Discursive psychology, focus group interviews, and participants' categories. British Journal of Developmental Psychology, 22: 499-507.

Ehrlich, Susan. 2002. Legal institutions, nonspeaking recipiency and participants' orientations. Discourse and Society 13: 731-747.

Emmison, Michael. 2013. 'Epistemic engine' versus 'Role-play Method': Divergent trajectories in contemporary conversation analysis. Australian Journal of Communication, 40:2, 5-7.

Enfield, Nick J. 2007. Meanings of the unmarked: How 'default' person reference does more than just refer. In Person reference in interaction: Linguistic, cultural and social perspectives, ed. Enfield, Nick J. and Stivers, Tanya, 97-120. Cambridge: Cambridge University Press.

Foucault, Michel. 1972. The archaeology of knowledge. London: Tavistock Publications. Frith, Hannah. 1998. Constructing the 'other' through talk. Feminism and Psychology, 8:4, $530-536$.

Garfinkel, Harold 1967. Studies in ethnomethodology. Englewood Cliffs, NJ: Prentice-Hall 
Heritage, John. 2012. The epistemic engine: Sequence organization and territories of knowledge. Research on Language and Social Interaction, 45:1, 30-52.

--- 2005. Conversation analysis and institutional talk. In Handbook of Language and Social Interaction, ed. Kristine L. Fitch and Robert E. Sanders, 103-147. Mahwah, NJ: Lawrence Erlbaum.

Holmes, Janet. 2007. Social constructionism, postmodernism and feminist sociolinguistics. Gender and Language, 1:1, 51-67.

Jefferson, Gail. 2004a. A note on laughter in 'male-female' interaction. Discourse Studies, 6: 117-133.

--- 2004b. Glossary of transcript symbols with an introduction. In Conversation analysis: Studies from the first generation, ed. Gene Lerner, 13-31. Amsterdam: John Benjamins.

--- 1987. On exposed and embedded correction in conversation. In Talk and social organization, ed. Graham Button and John R.E. Lee, 86-100. Clevedon: Multilingual Matters.

Jurik, Nancy C., and Siemsen, Cynthia. 2009. 'Doing gender' as canon or agenda: A symposium on West and Zimmerman. Gender and Society, 23:1, 72-75.

Kessler, Suzanne J., and McKenna, Wendy. 1978. Gender: An ethnomethodological approach. Chicago: University Of Chicago Press.

Kitzinger, Celia. 2008. Conversation analysis: Technical matters for gender research. In Gender and language research methodologies, ed. Kate Harrington, Lia Litosseliti, Helen Saunston and Jane Sunderland, 119-138. Basingstoke: Palgrave.

--- 2005. Heteronormativity in action: Reproducing the heterosexual nuclear family in afterhours medical calls. Social Problems, 524: 477-498.

Kitzinger, Celia and Frith, Hannah. 1999. Just say no? The use of conversation analysis in developing a feminist perspective on sexual refusal. Discourse and Society, 10: 3, 293- 
316.

Kulick, Don. 1999. Language and gender/sexuality. Language and Culture Mailing list:

Online Symposium. http://www.language-culture.org/archives/subs/kulickdon/index.html

Lakoff, Robin. 1973. Language and woman's place. Language in Society, 2: 45-79.

Land, Victoria and Kitzinger, Celia. 2011. Categories in talk-in-interaction: Gendering speaker and recipient. In Conversation and gender, ed. Susan A. Speer and Elizabeth Stokoe, 48-63. Cambridge University Press

--- 2007. Closet talk: The contemporary relevance of the closet in lesbian and gay interaction. In Out in psychology: Lesbian, gay, bisexual, trans and queer perspectives, ed. Victoria Clarke and Elizabeth Peel, 147 - 171. Chichester: Wiley.

--- 2005. Speaking as a lesbian: Correcting the heterosexist presumption. Research on Language and Social Interaction, 38: 371-416.

Leap, William. 1996. Word's out: Gay men's English. Minneapolis: University of Minnesota Press.

McIlvenny, Paul. ed. 2002. Talking gender and sexuality: Conversation, performativity and discourse in interaction. Amsterdam: John Benjamins.

Ochs, Elinor. 1992. Indexing gender. In Rethinking context, ed. Duranti, Alessandro and Goodwin, Charles, 335-358. Cambridge: Cambridge University Press.

Sacks, Harvey. 1992. Lectures on conversation Vols. I and II, edited by Gail Jefferson. Oxford: Blackwell.

--- 1984. Notes on methodology. In Structures of social action: Studies in conversation analysis, ed. J. Maxwell Atkinson and John Heritage, 2-27. Cambridge: Cambridge University Press. 
Schegloff, Emanuel A. 2007. Sequence organization in interaction: A primer in conversation analysis. Cambridge: Cambridge University Press.

--- 2001. Accounts of conduct in interaction: Interruption, overlap, and turn-taking. In Handbook of sociological theory, ed. John H. Turner, 287-321. New York: Kluwer Academic/Plenum.

--- 1997. Whose text? Whose context? Discourse and Society, 8:2, 165-187.

--- 1996. Issues of relevance for discourse analysis: Contingency in action, interaction and co-participant context. In Computational and conversational discourse: Burning issues - an interdisciplinary account, ed. Eduard H. Hovy and Donia R. Scott, 3-38. New York: Springer.

--- 1991. Reflections on talk and social structure. In Talk and social structure, ed. Deirdre Boden and Don Zimmerman, 44-70. Berkeley, CA: University of California Press. Sidnell, Jack. 2010. Conversation analysis: An introduction. Chichester: Wiley Blackwell.

--- 2003. Constructing and managing male exclusivity in talk-in-interaction. In The handbook of language and gender, ed. Janet Holmes and Miriam Meyerhoff, 327-352. Oxford: Blackwell.

Speer, Susan A. 2013. Talking about sex with patients in the Gender Identity Clinic: Implications for training and practice. Health, 17:6, 622-639.

--- 2011. On the role of reported, third party compliments in passing as a 'real' woman. In Conversation and gender, ed. Susan A. Speer and Elizabeth Stokoe, 155-182. Cambridge: Cambridge University Press.

--- 2005. Gender talk: Feminism, discourse and conversation analysis. London: Routledge.

--- 2002. Sexist talk: Gender categories, participants' orientations and irony. Journal of Sociolinguistics, 63: 347-377. 
Speer, Susan A. and Green, Richard. 2007. On passing: The interactional organization of appearance attributions in the psychiatric assessment of transsexual patients. In Out in psychology: Lesbian, gay, bisexual, trans and queer perspectives, ed. Victoria Clarke and Elizabeth Peel, 335-368. Chichester: Wiley.

Speer, Susan A. and Potter, Jonathan. 2000. The management of heterosexist talk: Conversational resources and prejudiced claims. Discourse and Society, 11:4, 543-572.

--- 2002. From performatives to practices: Judith Butler, discursive psychology, and the management of heterosexist talk. In Talking gender and sexuality, ed. Paul McIlvenny, 151-180. Amsterdam: John Benjamins.

Speer, Susan A. and Stokoe, Elizabeth. eds. 2011. Conversation and gender. Cambridge: Cambridge University Press.

Stivers, Tanya. 2008. Stance, alignment, and affiliation during storytelling: When nodding is a token of affiliation. Research on Language and Social Interaction, 41:1, 31-57.

Stokoe, Elizabeth. 2015. Identifying and responding to possible '-isms' in institutional encounters: Alignment, impartiality and the implications for communication training. Journal of Language and Social Psychology, 34:4, 427-445.

--- 2014. The Conversation Analytic Role-play Method CARM: A method for training communication skills as an alternative to simulated role-play. Research on Language and Social Interaction, 47:3, 255-265.

--- 2013. Applying findings and creating impact from conversation analytic studies of gender and communication. Economic and Industrial Democracy, 34:3, 537-552.

--- 2012. Moving forward with membership categorization analysis: Methods for systematic analysis. Discourse Studies, 14:3, 277-303. 
--- 2011. Simulated interaction and communication skills training: The 'Conversation Analytic Role-play Method'. In Applied conversation analysis: Changing institutional practices, ed. Charles Antaki, 119-139. Basingstoke: Palgrave Macmillan.

--- 2010. “Have you been married, or...?” Eliciting and accounting for relationship histories in speed-dating encounters. Research on Language and Social Interaction, 43:3, 260282.

--- 2009. Doing actions with identity categories: Complaints and denials in neighbour disputes. Text and Talk, 29:1, 75-97.

--- 2008. Categories and sequences: Formulating gender in talk-in-interaction. In Gender and language research methodologies, ed. Kate Harrington, Lia Litosseliti, Helen Saunston and Jane Sunderland, 139-157. Basingstoke: Palgrave.

Stokoe, Elizabeth and Edwards, Derek. 2007. "Black this, black that": Racial insults and reported speech in neighbour complaints and police interrogations. Discourse and Society, 18:3, 337-372.

Stokoe, Elizabeth and Sikveland, Rein O. 2015. Entering the customer's domestic domain: Enquiries about relationships at a window sales company. Conference paper, International Pragmatics Association, Antwerp, July.

Stokoe, Elizabeth, Sikveland, Rein O., and Huma, Bogdana. 2017, in press. Entering the customer's domestic domain: Categorial systematics and the identification of 'parties to a sale'. Journal of Pragmatics.

Stokoe, Elizabeth H. and Weatherall, Ann. eds. 2002. Gender, language, conversation analysis and feminism. Discourse and Society, 13:6.

Uchida, Aki. 1992. When "difference" is "dominance": A critique of the "anti-power-based" cultural approach to sex differences. Language and Society, 21: 547-568 
Velody, Irving and Williams, Robin. 1998. Introduction. In The politics of constructionism, ed. Irving Velody and Robin Williams, 1-12. London: Sage.

Weatherall, Ann. 2015. Sexism in language and talk-in-interaction. Journal of Language and Social Psychology, 34:4, 410-426.

--- 2000. Gender relevance in talk-in-interaction and discourse. Discourse and Society, 11:2, 286-288.

West, Candace and Zimmerman, Don H. 2009. Account for Doing Gender. Gender and Society, 23:1, 112-122.

--- 1987. Doing gender. Gender and Society, 1:125-151.

Wetherell, Margaret. 2007. A step too far: Discursive psychology, linguistic ethnography and questions of identity. Journal of Sociolinguistics, 11:5, 661-681.

--- 1998. Positioning and interpretative repertoires: Conversation analysis and poststructuralism in dialogue. Discourse and Society, 9:3, 431-456.

Whitehead, Kevin A. 2015. Everyday antiracism in action: Preference organization in responses to racism. Journal of Language and Social Psychology, 34:4, 374-389.

Wilkinson, Sue. 2015. Sexuality and talk-in-interaction. In The international encyclopedia of human sexuality, ed. Patricia Whelehan and Anne Bolin,1115-1354. Chichester: Wiley.

Wilkinson, Sue and Kitzinger, Celia. 2007. Conversation analysis, gender and sexuality. In Language, discourse and social psychology, ed. Ann Weatherall, Bernadette Watson and Cindy Gallios, 206-230. Palgrave Macmillan.

Zimmerman, Don H. 1992. They were all doing gender, but they weren't all passing: Comment on Rogers. Gender and Society, 6:2, 192-198. 